\title{
Argamassas de cal e terra: características e possibilidades de aplicação
}

\author{
Lime-earth mortars: characteristics and applications
}

\begin{abstract}
Paulina Faria
Resumo

dmite-se como hipótese que as argamassas mistas de cal e terra tenham 1 resultado da prática profissional quando as condições económicas 1 possibilitaram a adição de cais às argamassas vernáculas só de terra, que são susceptíveis à ação da água. Em estudos anteriores verificouse que a adição de baixos teores de cal aérea a argamassas de terra de cor escura, embora tornem as argamassas resistentes à água, conduzem a alterações da sua cor para tom mais claro e redução de resistências mecânicas. Neste estudo avalia-se o efeito que substituições de cal aérea por uma terra local caulinítica apresentam em argamassas de cal ao traço volumétrico 1:2, correspondendo a argamassas com traço em massa de 1:8, com substituições de $10 \%$ a 50\%. As argamassas têm, pela sua formulação, menor energia incorporada e demonstram ser adequadas para aplicação em rebocos de edifícios antigos e mesmo em construção nova com características compatíveis. Os resultados da caracterização mecânica, física e por ataque de sulfatos foram positivos para uma substituição de $10 \%$, variando percentualmente entre propriedades, mas muito há ainda a investigar para um conhecimento aprofundado deste tipo de argamassas mistas de cal e terra, muito utilizadas no passado, com vista à otimização de formulações que possam vir a ser aplicadas correntemente.

Palavras-chave: Cal aérea. Terra argilosa. Alvenaria. Reboco. Refechamento de junta.

Abstract

Earth-lime mortars probably result from professional practices from the time when economical conditions enabled the addition of air lime to vernacular earth mortars, which are not durable when in contact with water. Previous studies have shown that the addition of low contents of air lime on earth mortars with dark colour, while turning the mortars water resistant, makes their colour lighter and weakens their mechanical characteristics. This study examines the partial weight replacement of lime by a local earth in air lime mortars with a 1:2 lime: sand volumetric proportion, corresponding to mortars with a 1:8 weight proportion, with replacements from 10 to $50 \%$. The embodied energy of mortars is reduced by their formulation, and they are adequate for use as render in old buildings and also on new constructions with compatible characteristics. The results of the

1, 2Paulina Faria ${ }^{1}$ CERIS

${ }^{2}$ Universidade NOVA de Lisboa Caparica - Portugal

Recebido em 01/12/17 Aceito em 28/05/18 mechanical and physical characteristics, as well as on the reaction to sulphates attack, were particularly positive for a $10 \%$ lime replacement by earth, with variations between the assessed properties. Nevertheless, further research is still needed for a deeper knowledge of the characteristics of lime-earth mortars, widely used in the past, in order to optimise formulations to be applied in the present day.

Keywords: Air lime. Clayish earth. Masonry. Render. Repointing.
\end{abstract}




\section{Introdução}

Uma argamassa é efetuada a partir de uma mistura de agregados relativamente finos com um ligante e água. No entanto, podem ser incluídos outros materiais na sua formulação, para otimização face ao tipo de aplicação em causa. As argamassas podem ser utilizadas no assentamento de blocos em alvenarias, no tratamento de juntas e em rebocos interiores e exteriores. Têm de possuir características que sejam compatíveis com as dos materiais sobre os quais vão ser aplicadas, com as solicitações a que vão estar sujeitas e com os requisitos que são função do tipo de aplicação (VEIGA, 2017).

Nas paredes da taipa,de alvenarias de adobe ou de pedra irregular argamassada, de pau a pique ou taipa de mão (tabique) era corrente utilizarem-se antigamente argamassas só de terra em rebocos interiores. Em rebocos exteriores e no assentamento e tratamento de juntas de alvenarias usavam-se argamassas mistas de terra e cal aérea ou argamassas só de cal aérea. A cal era geralmente utilizada na forma de pasta (FARIA; HENRIQUES; RATO, 2008).

$\mathrm{Na}$ atualidade as argamassas de terra são muito utilizadas em alguns países desenvolvidos, como é o caso, na Europa, da Alemanha, Itália ou França, em rebocos interiores de construções novas ou na reabilitação de construções existentes. $\mathrm{O}$ incremento da sua utilização deve-se particularmente a preocupações de ecoeficiência e qualidade do ar ambiente que estas argamassas de terra otimizam (DARLING et al., 2012; MELIÀ et al., 2014; LIMA, FARIA, 2016; LIMA; FARIA; SANTOS SILVA, 2016). Assim, as argamassas com base em terra têm voltado a ser usadas para o refechamento de juntas de assentamento de alvenarias históricas (MORTON; LITTLE, 2013), para a reparação das superfícies das paredes de terra (GOMES, 2013) e para rebocos (HAMARD et al., 2013; FARIA; SANTOS; AUBERT, 2016; FARIA; LIMA, 2018).

Nas argamassas só de terra, são as partículas argilosas da terra que funcionam como aglutinante, tendo o papel de ligante natural. Em função das características observadas, verifica-se que a sua utilização não se restringe à aplicação em paredes realizadas com base em terra, mas pode estenderse a outros suportes. Faria, Santos e Silva (2014) mostraram o bom comportamento apresentado por um reboco de terra aplicado sobre paredes de alvenaria com materiais mais ou menos correntes, como o bloco cerâmico (tijolo furado), blocos de betão, adobes ou alvenaria de pedra argamassada antiga. Estes últimos casos são frequentes em edifícios mais antigos, na maioria dos casos com necessidades de intervenção com vista à sua conservação e manutenção.

Mas as argamassas só de terra (não estabilizadas, nomeadamente com ligante) têm como principal desvantagem a sua suscetibilidade à água, que pode conduzir à "lavagem" do ligante (GOMES; GONÇALVES; FARIA, 2016; FARIA; LIMA, 2018), e suscetibilidade biológica, principalmente se contêm fibras naturais (SANTOS; NUNES; FARIA, 2017). Para a sua estabilização podem ser aplicados tratamentos de superfície ou adicionados produtos distintos à formulação, tal como um ligante corrente ou uma mucilagem. $\mathrm{O}$ ligante que era tradicionalmente adicionado era a cal aérea.

As argamassas mistas, de terra e cal aérea, podiam resultar assim de formulação específica em que a cal era misturada com uma terra (mais ou menos arenosa) em vez de areia. É muito provável que, partindo de argamassas vernáculas de terra, e quando as condições económicas o permitiam, adições sucessivamente mais elevadas de cal a estas argamassas tenham resultado nas argamassas de cal aérea que existem em muitos edifícios antigos. Estas identificam-se por vezes por terem agregado muito argiloso, mesmo após "lavagem" parcial destas partículas finas por envelhecimento e exposição das argamassas.

Atualmente, as argamassas mistas de terra e cal aérea, comparativamente a argamassas só de cal aérea, podem apresentar vantagens económicas, ambientais e técnicas. São vantagens ambientais e económicas poderem utilizar-se na formulação das argamassas menores teores de ligante produzido especificamente (a cal aérea), substituindo-o parcialmente por terra argilosa. A terra idealmente provirá de escavações para trabalhos de construção e é classificada como resíduo de construção e demolição (RCD) inerte. Dessa forma reduz-se o volume de RCD a gerir. Podem também utilizar-se menores teores de areia explorada especificamente e transportada, substituindo-a parcialmente pela terra argilosa escavada. São vantagens técnicas a obtenção de adequada trabalhabilidade, retração controlada, resistências mecânicas relativamente baixas, que lhes propiciam compatibilidade com uma grande gama de suportes com boa aderência e resistência às ações correntes. Mas estas argamassas têm ainda a vantagem de se apresentarem ligeiramente pigmentadas (pela terra), o que pode ser muito interessante para determinados tipos de aplicações, nomeadamente em rebocos não pintados e no tratamento de juntas.

Embora argamassas mistas de terra e cal aérea sejam diversas vezes referidas em bibliografia 
genérica, não têm sido objeto de caracterização sistemática. Para além disso, cada terra apresenta as suas particularidades específicas, o que multiplica a diversidade das características obtidas (CARDOSO; EIRES; CAMÕES, 2013). Para contribuir para um maior conhecimento das características destas argamassas desenvolveramse duas linhas de investigação, nas quais se partiu de dois extremos: argamassas só de terra e argamassas só de cal aérea. Nas argamassas só de terra, Gomes, Faria e Gonçalves (2018) avaliaram a influência da adição de baixas percentagens de cal aérea a uma argamassa de terra caulinítica, enquanto Santos, Nunes e Faria (2017) avaliaram situação similar, mas a argamassa de terra ilítica. Nas argamassas com base em cal aérea, Faria et al. (2013, 2015) iniciaram a avaliação da influência de substituições parciais de cal por uma terra caulinítica (a mesma utilizada na linha de investigação anteriormente referida) pela aplicação de painéis de rebocos sobre um murete de taipa. Pretende-se contribuir para um mais amplo conhecimento que permita compreender o desempenho de argamassas mistas de cal e terra em edifícios antigos. Dentro do possível, procurase promover uma mais abrangente aplicação de argamassas de cal com substituições parciais por terra caulinítica. Assim, apresenta-se neste artigo um estudo de caracterização efectuado com este tipo de argamassas. Para além da observação visual do estado dos rebocos aplicados no murete ao fim de cinco anos (2013-2017), apresentam-se os resultados da caracterização destas argamassas a partir de provetes em laboratório.

\section{Materiais utilizados}

A cal aérea hidratada em pó utilizada (CL) foi disponibilizada pela empresa Lusical (Grupo Lhoist). Trata-se de uma cal aérea calcítica, como se pode observar pela composição química apresentada na Tabela 1 .

A areia utilizada nestas argamassas é resultante da mistura de três areias siliciosas lavadas e graduadas, de granulometrias distintas: APAS12, APAS20 e APAS30 comercializadas pela Areipor, Portugal. As suas curvas granulométricas foram apresentadas em Pimenta et al. (2014). Na formulação das argamassas as areias foram misturadas na proporção 1:1,5:1,5 respectivamente de APAS12:APAS20:APAS30. A terra utilizada (t) foi selecionada por Gomes (2013) entre várias disponibilizadas pela empresa Sorgila - Sociedade de Argilas, por apresentar baixa retração. É proveniente de Rendinha, Pombal, Portugal, e foi desterroada após remoção manual das partículas mais grossas. A sua caracterização por difração de raios $X(D R X)$, apresentada na Tabela 2, mostra tratar-se de uma terra com argila maioritariamente caulinítica.

A curva granulométrica resultante da peneiração a húmido e a seco da terra e da mistura das areias é apresentada na Figura 1.

A massa específica (baridade) de todos os constituintes secos das argamassas, determinada com base na EN 1015-1 (COMITE..., 1998), é apresentada na Tabela 3 .

Tabela 1 - Composição química da cal aérea em \% de massa utilizada nas argamassas

\begin{tabular}{c|c|c|c|c|c|c|c|c|c|c|c}
\hline$\%$ massa & $\mathrm{SiO}_{2}$ & $\mathrm{Al}_{2} \mathrm{O}_{3}$ & $\mathrm{Fe}_{2} \mathrm{O}_{3}$ & $\mathrm{MnO}$ & $\mathrm{MgO}$ & $\mathrm{CaO}$ & $\mathrm{Na}_{2} \mathrm{O}$ & $\mathrm{K}_{2} \mathrm{O}$ & $\mathrm{TiO}_{2}$ & $\mathrm{P}_{2} \mathrm{O}_{5}$ & $\begin{array}{c}\text { Perda } \\
\text { Fogo }\end{array}$ \\
\hline Cal aérea & - & 0,01 & 0,15 & 0,01 & 3,09 & 76,74 & - & 0,02 & 0,04 & 0,01 & 20,45 \\
\hline
\end{tabular}

Fonte: Gameiro et al. (2013).

Tabela 2 - Composição mineralógica por DRX da fração fina da terra utilizada nas argamassas

\begin{tabular}{|c|c|c|c|c|c|c|c|c|c|}
\hline Qualitativo & Quartzo & Feldspato & Mica/ilite & Clorite & Caulinite & Goetite & Anatase & Anfibole & Hematite \\
\hline Terra & +++ & Vest. & Vest. & $?$ & ++ & + & +/Vest. & - & - \\
\hline $\begin{array}{l}\text { Fonte: Gomes } \\
\text { Nota: Legend } \\
\qquad \begin{aligned}+++ \\
++ \text { t } \\
+ \text { ba } \\
\text { Vest } \\
\text { ? dú } \\
\text { - nã }\end{aligned}\end{array}$ & $\begin{array}{l}\text { Faria e Go } \\
\text { : } \\
\text { levado teo } \\
\text { or interméc } \\
\text { xo teor; } \\
\text { vestígios; } \\
\text { ida na pres } \\
\text { detectado }\end{array}$ & $\begin{array}{l}\text { calves }(201 \varepsilon \\
\text { ç̧a; e }\end{array}$ & & & & & & & \\
\hline
\end{tabular}


Figura 1 - Curvas granulométricas da mistura das areias e da terra, determinada por via húmida e seca, tal como inserida na mistura

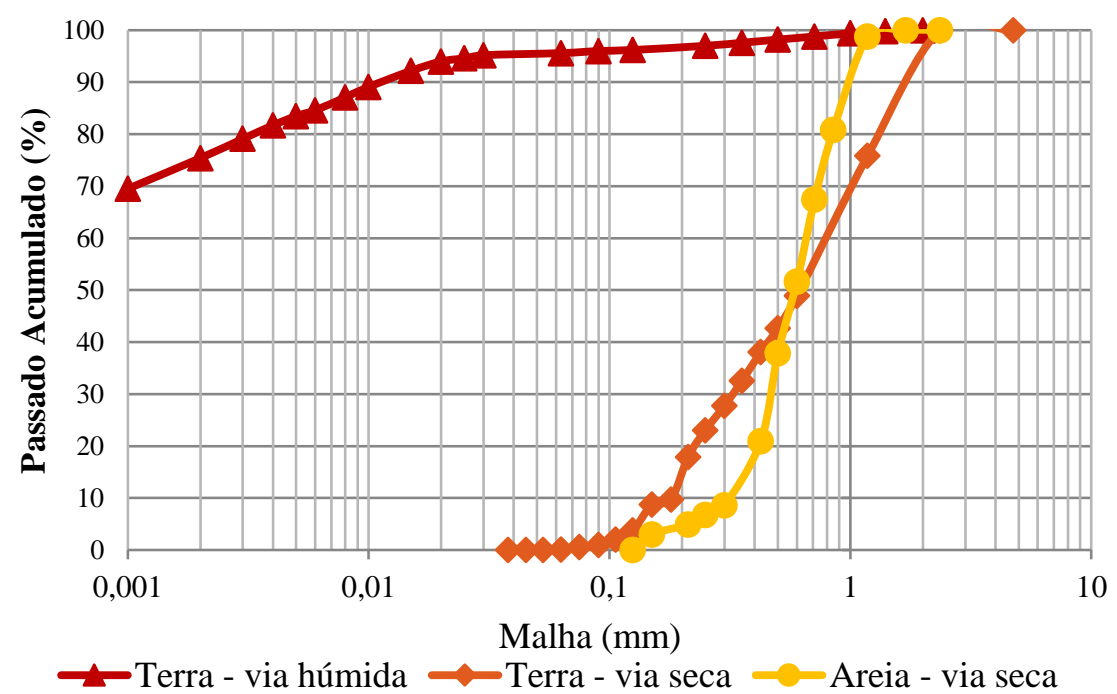

Fonte: Pimenta et al. (2014).

Tabela 3 - Massa específica da cal aérea, terra desterroada e areias das argamassas

\begin{tabular}{l|c|c|c|c|c}
\hline \multirow{2}{*}{ Baridade } & \multirow{2}{*}{ Cal aérea } & \multirow{2}{*}{ Terra } & \multicolumn{3}{|c}{ Areias } \\
\cline { 4 - 6 } & & & APAS12 & APAS20 & APAS30 \\
\hline $\mathbf{k g} / \mathbf{d m}^{\mathbf{3}}$ & 0,362 & 1,084 & 1,412 & 1,405 & 1,388 \\
\hline
\end{tabular}

Realizaram-se duas argamassas de referência só de cal aérea, com traços volumétricos de cal:areia 1:2 (argamassa CL2) e 1:3 (argamassa CL3). Com base na formulação da argamassa ao traço 1:2, realizaram-se substituições parciais da massa de cal por terra: $5 \%, 10 \%, 25 \%$ e $50 \%$ (argamassas CL2_5t a CL2_50t), conforme apresentado na Tabela 4.

Para a amassadura das argamassas, e através da massa específica, determinaram-se as massas dos constituintes secos de cada formulação, que foram homogeneizados manualmente. A amassadura mecânica iniciou-se em simultâneo com a adição da água de amassamento (ou amassadura), durante os 20 segundos iniciais. A água de amassadura foi adicionada de forma a obter-se a consistência por espalhamento de $150 \pm 5 \mathrm{~mm}$ (Tabela 4), determinada com base na EN 1015-3 (COMITE..., 1999) com mesa de espalhamento de acordo com a versão de 1999 desta norma. A amassadura mecânica foi interrompida ao fim de 150 segundos, o material junto aos bordos foi integrado manualmente na argamassa e foi realizada amassadura mecânica por mais 30 segundos.

Com cada argamassa foram produzidos três provetes prismáticos com dimensões de $40 \mathrm{~mm} \mathrm{x}$ 40 mm x 160 mm, com compactação mecânica em duas camadas, e dois provetes constituídos por uma camada de argamassa com cerca de $2 \mathrm{~cm}$ de espessura aplicada sobre uma superfície de bloco cerâmico (tijolo furado) com área de cerca de 20 $\mathrm{cm}$ x $30 \mathrm{~cm}$, após aspersão prévia com água. Para a execução destes provetes de argamassa sobre bloco cerâmico, esta foi deixada cair por ação da gravidade de uma altura constante de $70 \mathrm{~cm}$, e depois, com a desempenadeira (talocha), a camada de argamassa foi acomodada e regularizada, simulando um reboco de camada única (Figura 2).

Todos provetes foram colocados numa sala condicionada, a temperatura de $20 \pm 2 \quad{ }^{\circ} \mathrm{C}$ e humidade relativa (HR) de $65 \pm 5 \%$, sendo aspergidos com água diariamente durante os primeiros 4 dias. Os provetes prismáticos foram desmoldados e permaneceram na sala de cura até aos 90 dias, juntamente com os provetes de argamassa sobre bloco cerâmico. Foram ensaiados aos 90 dias de idade.

\section{Procedimentos de ensaio utilizados}

Realizou-se uma observação visual periódica ao longo de 5 anos do estado de um painel de reboco de argamassa de cal e $25 \%$ de terra em comparação com o só de cal aérea. O comportamento das argamassas simulando um reboco foi observado visualmente nos provetes sobre bloco cerâmico. Efetuaram-se ensaios de 
caracterização em provetes prismáticos; apenas o ensaio de condutibilidade térmica foi executado nos provetes sobre bloco cerâmico. A Figura 3 apresenta em esquema os ensaios e os correspondentes provetes utilizados.

Três provetes prismáticos de cada argamassa foram utilizados para determinação da massa volúmica, módulo de elasticidade dinâmico e resistência à flexão. Uma das metades resultantes de cada provete foi utilizada para determinação da resistência à compressão e uma parte íntegraresultante desse ensaio foi utilizada para a determinação da porosidade aberta. A outra metade dos três provetes foi utilizada para determinação da absorção de água por capilaridade, secagem e, posteriormente, resistência aos sulfatos.

Todos estes ensaios foram realizados em três provetes e os resultados são expressos pela média (e desvio-padrão) dos valores obtidos.

A porosimetria de mercúrio e a análise por difração de raios $\mathrm{X}$ e análise termogravimétrica (TGA-DTG) foram realizadas apenas num provete por argamassa, a partir de pequenas amostras resultantes dos meios provetes utilizados no ensaio de compressão.

Tabela 4 - Traços em massa e em volume, razões água/(cal e terra) e água/terra e consistência por espalhamento das argamassas

\begin{tabular}{|c|c|c|c|c|c|}
\hline \multirow[b]{2}{*}{ Argamassa } & \multicolumn{2}{|c|}{ CL:terra:Areia* } & \multirow[b]{2}{*}{ Água/(CL+t) [-] } & \multirow[b]{2}{*}{ Água/t [-] } & \multirow{2}{*}{$\begin{array}{c}\text { Consist. } \\
\text { espalh. } \\
{[\mathrm{mm}]}\end{array}$} \\
\hline & $\begin{array}{c}\text { Traço em } \\
\text { massa }\end{array}$ & $\begin{array}{c}\text { Traço em } \\
\text { volume }\end{array}$ & & & \\
\hline CL2 & $1: 0: 7,7$ & $1: 0: 2$ & 0,17 & - & 147 \\
\hline CL2_5t & $1: 0,05: 8,1$ & $1: 0,02 ; 2,1$ & 0,18 & 35,4 & 150 \\
\hline CL2_10t & $1: 0,1: 8,6$ & $1: 0,04: 2,2$ & 0,18 & 17,7 & 155 \\
\hline CL2_25t & $1: 0,3: 10,3$ & $1: 0,1: 2,7$ & 0,18 & 7,1 & 150 \\
\hline CL2_50t & $1: 1: 15,5$ & $1: 0,3: 4$ & 0,18 & 3,5 & 149 \\
\hline CL3 & $1: 0: 11,6$ & 1:0:3 & 0,25 & - & 151 \\
\hline
\end{tabular}

Nota: *considerou-se a massa resultante da soma das três areias APAS12, APAS20 e APAS30 utilizadas na mistura de areias, com os correspondentes arredondamentos.

Figura 2 - Provete de argamassa sobre bloco cerâmico (esq.) e meios provetes prismáticos em ensaio de sulfatos, ilustrando a pigmentação natural pela terra (dir.)
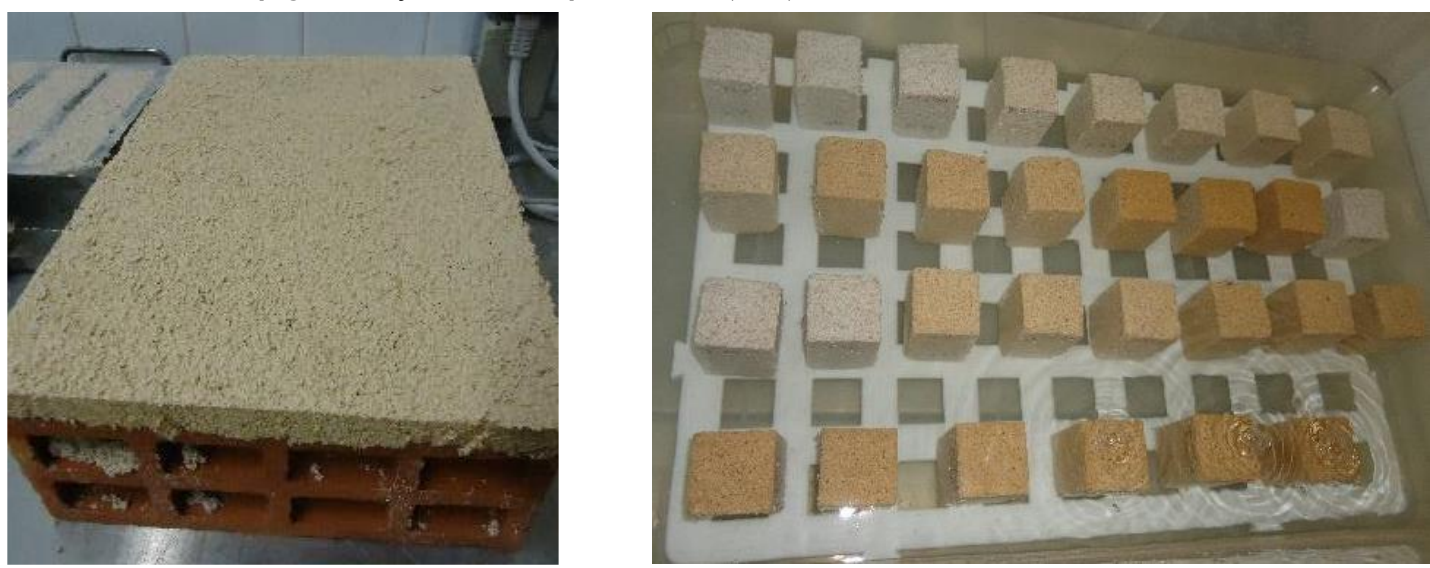

Figura 3 - Esquema da caracterização efetuada com os provetes

Massa volúmica
Condutibilidade térmica
Módulo de elasticidade dinâmico
Resistência à tração

Resistência à tração
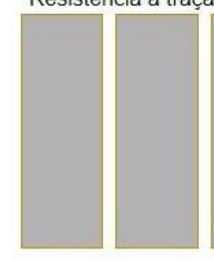

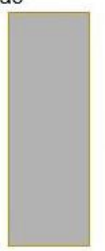

Resultante da Rt

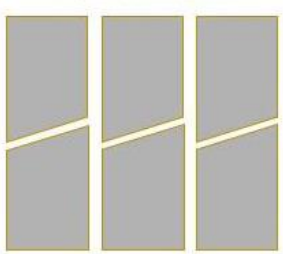

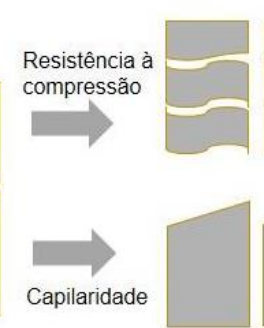

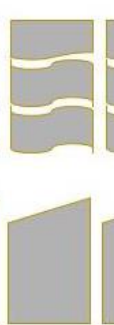

Porosidade aberta e massa

volúmica aparente

$\Rightarrow$ XRD e TGA-DTG

$\Rightarrow$ Porosimetria de mercúrio

Secagem

Resistência aos sulfatos 


\section{Ensaios mecânicos}

O módulo de elasticidade dinâmico (Ed) foi determinado, de forma não destrutiva, com base na NP EN 14146 (INSTITUTO..., 2006), utilizando o equipamento Zeus Resonance Meter. Cada provete prismático foi colocado com um topo em contacto com o recetor e outro com o emissor e atravessado por onda ultrassónica. Com base na massa e na dimensão do provete, o equipamento calculou diretamente o valor de Ed a partir da frequência de ressonância. Com cada provete, alterando a sua posição no equipamento, realizaram-se 4 medidas.

Os mesmos provetes foram utilizados para a determinação da resistência à tração por flexão por 3 pontos, com base na EN 1015-11 (COMITE..., 1999), num equipamento Zwick Rowell Z050 com uma célula de carga de $2 \mathrm{kN}$.

Uma metade resultante de cada provete foi ensaiada de acordo com a mesma norma à compressão, utilizando o mesmo equipamento, com dispositivo com secção de $40 \mathrm{~mm}$ x $40 \mathrm{~mm}$ e célula de carga de $50 \mathrm{kN}$.

\section{Ensaios microestruturais e mineralógicos}

Um topo íntegro resultante de cada provete submetido ao ensaio de compressão foi utilizado para a determinação da porosidade aberta e da massa volúmica, com base na NP EN 1936 (INSTITUTO..., 2008). Foi aferida a massa seca dos provetes e estes foram inseridos num exsicador sob vácuo. Ao fim de $24 \mathrm{~h}$ foi introduzida água lentamente, até imersão completa dos provetes. Após $24 \mathrm{~h}$ a pressão foi libertada e, após novas 24 $\mathrm{h}$, a massa dos provetes foi aferida em imersão (pesagem hidrostática) e com estes saturados de água.

Uma amostra íntegra de cada argamassa foi cortada de forma a preencher o mais possível o recipiente do penetrómetro de vidro a ensaiar por porosimetria de mercúrio. Foi utilizado um equipamento Micrometritics Autopore II, com baixas pressões de 0,014-0,207 $\mathrm{MPa}$ e altas pressões de 0,276-206,843 $\mathrm{MPa}$. O resultado apresenta-se na forma de curvas de intrusão incremental de mercúrio, função do diâmetro dos poros.

Foi desagregada e moída uma amostra de cada argamassa, incluindo os grãos de areia, de modo a garantir que todas a partículas passavam no peneiro de malha $106 \mu \mathrm{m}$. Deste modo obtiveramse as amostras globais para o ensaio de DRX e para a análise termogravimétrica. Os difractogramas de raios $\mathrm{X}$ foram obtidos através de um difractómetro de raios X Philips PW 3710 com $35 \mathrm{kV}$ e $45 \mathrm{~mA}$, utilizando radiação $X$ com comprimento de onda $\lambda$ de $1,7903 \AA$. Para a análise ATG-DTG foi utilizada uma termobalança SETARAM TGA 92 com atmosfera inerte de árgon e velocidade de aquecimento de $10^{\circ} \mathrm{C} / \mathrm{min}$ desde a temperatura ambiente até aos $1000^{\circ} \mathrm{C}$.

\section{Ensaios físicos}

A condutibilidade térmica $(\lambda)$ foi determinada aos 90 dias de idade das argamassas, através do equipamento ISOMET 2104 Heat Transfer Analyzer, com uma sonda de contacto API 210412 com área circular com $60 \mathrm{~mm}$ de diâmetro, aplicada nos provetes de argamassa sobre bloco cerâmico, colocados sobre uma placa de isolamento térmico. Esta propriedade é pouco importante para argamassas aplicadas em rebocos de espessura reduzida, mas a sua influência aumenta com a espessura com que a argamassa é aplicada, nomeadamente quando no assentamento de blocos de alvenaria.

A metade dos provetes prismáticos resultante do ensaio de resistência à flexão, não utilizada para a compressão, foi utilizada para determinação da capilaridade e secagem.

O ensaio de capilaridade foi realizado com base na EN 1015-18 (COMITE..., 2002) e na EN 15801 (COMITE..., 2009). As faces laterais de cada provete foram envoltas em filme de polietileno, de forma a bloquear a evaporação de água por essas superfícies e garantir ascensão capilar unidirecional. Foi aplicada uma gaze, mantida por um elástico, na base do provete, sobre o polietileno. A massa constante seca dos provetes foi aferida e a sua base foi colocada em contacto com uma lâmina de água de $5 \mathrm{~mm}$, no instante de tempo 0 segundos. Foram aferidas as massas dos provetes a intervalos de tempo definidos após contacto com a água. O ensaio foi considerado concluído quando a massa estabilizou. A variação de massa por unidade de área em contacto com a água possibilitou a elaboração da curva de capilaridade de cada provete e a curva média de cada argamassa. O coeficiente de capilaridade resultou do declive do segmento inicial mais representativo dessa curva e traduz a velocidade com que ocorre a absorção capilar, enquanto o valor assintótico da curva traduz a absorção total de água por capilaridade.

O ensaio de secagem iniciou-se com a aferição da massa saturada de cada provete, após a remoção do respetivo provete do contacto com a água e da gaze da base dos provetes, com base na EN 16322 (COMITE..., 2013). A massa dos provetes foi aferida a intervalos definidos a partir do instante 0 
s da pesagem inicial de secagem, com o topo dos provetes colocado em contacto com uma superfície metálica e impermeável, na sala condicionada (20 ${ }^{\circ} \mathrm{C}$ e $65 \%$ HR). Determinou-se a curva de secagem de cada provete e de cada argamassa, com base no tempo (em abcissa) e variação de massa por área de secagem em ordenada. $O$ declive com a horizontal do segmento inicial de cada curva define a taxa de secagem na fase inicial de secagem. A curva de secagem possibilita também a determinação do índice de secagem, que diminui com a facilidade de secagem global.

\section{Ensaio de resistência ao ataque por sulfatos}

Foram dissolvidos $329 \mathrm{~g}$ de sulfato de sódio anidro em 10 litros de água potável, correspondendo a $3,09 \%$ - metade da dosagem indicada na NP EN 12370 (INSTITUTO..., 2001). Foi seguido o procedimento descrito por Faria (2009) e utilizados os provetes resultantes dos ensaios de capilaridade e secagem. Após remoção do filme de polietileno os provetes foram secos em estufa a $105^{\circ} \mathrm{C}$ até massa constante. Após pesagem, os provetes foram imersos na solução durante $2 \mathrm{~h}$ (Figura 2), escorridos e secos novamente em estufa, durante um mínimo de $21 \mathrm{~h}$, após as quais a massa foi avaliada. Após cerca de 35-40 minutos de arrefecimento, o ciclo foi repetido. Realizaram-se 25 ciclos. Os resultados são expressos graficamente pela curva que apresenta a variação de massa em função do número de ciclos.

\section{Resultados e discussão}

Por observação visual durante cinco anos em exposição natural verificou-se que o painel de reboco de cal com $25 \%$ de terra em substituição de massa equivalente de cal não apresentou degradação distinta da do painel de reboco só de cal áerea.
Os restantes resultados dos ensaios são expressos pela média (e desvio-padrão) dos valores obtidos, sempre que um mínimo de três ensaios foi realizado.

\section{Características mecânicas}

Apresentam-se na Tabela 5 as características mecânicas das argamassas. O módulo de elasticidade dinâmico $(\mathrm{Ed})$ e a resistência à compressão (Rc) são diretamente proporcionais, apresentando as mesmas tendências entre as argamassas. Verifica-se existir uma tendência para valores de Ed e Rc semelhantes em argamassas com percentagens de substituição de cal por terra até $10 \%$, e uma diminuição com as substituições de $25 \%$ e $50 \%$. Embora apenas ensaiadas aos 90 dias, e não aos 28 dias como especificado na norma NP EN 998-1 (INSTITUTO..., 2013a) para rebocos, todas as argamassas ensaiadas indiciam poder classificar-se como CS I relativamente à resistência à compressão (mínimo de $0,4 \mathrm{~N} / \mathrm{mm}^{2}$ ). No entanto, de acordo com a NP EN 998-2 (INSTITUTO..., 2013b) as argamassas não são classificáveis como argamassas de assentamento do ponto de vista da resistência à compressão pois não atingem o mínimo de $1 \mathrm{~N} / \mathrm{mm}^{2}$. Chama-se, no entanto, a atenção que as normas NP EN 998 são essencialmente aplicáveis a argamassas industriais formuladas com base cimentícia, o que não é o caso das argamassas em estudo.

Quanto à resistência à tração por flexão (Rf), muito importante relativamente à resistência à fendilhação das argamassas quando aplicadas em rebocos, ocorre um acréscimo positivo com a substituição de cal por $10 \%$ de terra. A razão Rf/Ed é assim bastante elevada para esta argamassa, indiciando um bom comportamento por traduzir uma boa resistência à tração por flexão e uma boa deformabilidade. A argamassa com substituição mássica de $25 \%$ de cal por terra ainda apresenta uma resistência ligeiramente superior à argamassa de referência ao traço volumétrico 1:3.

Tabela 5 - Módulo de elasticidade dinâmico, resistências à flexão e à compressão, massa volúmica aparente, porosidade aberta e condutibilidade térmica das argamassas

\begin{tabular}{|c|c|c|c|c|c|c|c|c|c|c|c|c|}
\hline \multirow{2}{*}{ Arg. } & \multicolumn{2}{|c|}{$\operatorname{Ed}\left[\mathbf{N} / \mathbf{m m}^{2}\right]$} & \multicolumn{2}{|c|}{$\operatorname{Rf}\left[\mathrm{N} / \mathrm{mm}^{2}\right]$} & \multicolumn{2}{|c|}{$\operatorname{Rc}\left[\mathbf{N} / \mathrm{mm}^{2}\right]$} & \multicolumn{2}{|c|}{$\mathrm{MV}\left[\mathrm{kg} / \mathrm{m}^{3}\right]$} & \multicolumn{2}{|c|}{ Pab [\%] } & \multicolumn{2}{|c|}{$\lambda[\mathbf{W} /(\mathbf{m} . \mathbf{K})]$} \\
\hline & Med & Dp & Med & Dp & Med & Dp & Med & Dp & Med & Dp & Med & Dp \\
\hline CL2 & 2902 & 48 & 0,33 & 0,02 & 0,70 & 0,14 & 1594 & 9 & 29,4 & 0,4 & 0,74 & 0,01 \\
\hline CL2_5t & 2880 & 53 & 0,31 & 0,02 & 0,64 & 0,06 & 1552 & 7 & 31,0 & 0,3 & 0,73 & 0,03 \\
\hline CL2_10t & 2914 & 42 & 0,35 & 0,02 & 0,72 & 0,02 & 1560 & 4 & 30,9 & 0,2 & 0,77 & 0,10 \\
\hline CL2_25t & 2662 & 34 & 0,31 & 0,02 & 0,57 & 0,03 & 1576 & 11 & 30,3 & 0,3 & 0, & 0,01 \\
\hline CL2_50t & 2229 & 90 & 0,24 & 0,01 & 0,51 & 0,04 & 1579 & 3 & 29,7 & 0,1 & 0,69 & 0,04 \\
\hline $\mathrm{CL}^{-}{ }^{-}$ & 3243 & 56 & 0,30 & 0,03 & 0,66 & 0,04 & 1596 & 6 & 28,6 & 0,2 & 0,77 & 0,03 \\
\hline
\end{tabular}


Comparam-se os resultados de caracterização mecânica obtidos no presente estudo com os de argamassas caracterizadas por Gomes, Faria e Gonçalves (2018) - realizadas com a mesma terra, com outra areia e aos traços em volume de 1:3 e em massa de 1:3,8 (terra: areia), com adições em massa de $0 \%, 5 \%, 10 \%$ e $15 \%$ da mesma cal aérea.Verifica-se que, enquanto as argamassas de cal não são prejudicadas com a substituição até $25 \%$ de cal por terra, já nas argamassas de terra a adição de $5 \%$ de cal baixa drasticamente todas as caracteristicas mecânicas, sendo essa redução um pouco menor para adições de $10 \%$ e $15 \%$ de cal.

\section{Características microestruturais e mineralógicas}

Apresentam-se na Tabela 5 a massa volúmica (MV) e a porosidade aberta (Pab) das argamassas, que são inversamente proporcionais. No entanto, entre as argamassas de referência aos traços 1:2 e 1:3 observam-se valores muito próximos apesar de CL3, por conter menos ligante, ser potencialmente mais porosa, o que não é demonstrado pelo resultado destes ensaios. Aparentemente, e admitindo que o processo de ensaio não propicia a lavagem significativa de finos da terra, há uma redução acentuada de massa volúmica com a substituição de $5 \%$ de cal por terra, redução essa que se vai diluindo gradualmente com o aumento da substituição.

A Figura 4 apresenta os resultados da porosimetria de mercúrio, em termos de intrusão incremental em função do diâmetro dos poros. Verifica-se que a microestrutura das argamassas de referência também surge muito semelhante, validando os resultados antes apresentados da massa volúmica e porosidade aberta. O comportamento mais diferenciado é apresentado pelas argamassas com $50 \%$ e $5 \%$ de terra em substituição da cal, cuja intrusão principal não ocorre na gama dos $0,8 \mu \mathrm{m}$, tal como nas restantes argamassas, apresentando-se numa gama um pouco inferior. De entre as argamassas com intrusão incremental maioritariamente na gama dos $0,8 \mu \mathrm{m}$ sobressai ligeiramente a argamassa com $10 \%$ de terra com um maior pico nessa gama. Ressalva-se, no entanto, estes resultados terem sido obtidos apenas com análise de uma amostra por argamassa e não traduzirem, assim, um valor médio.

A Figura 5 apresenta os difractogramas de raios $\mathrm{X}$ das argamassas ao traço volumétrico 1:2.

Na Figura 6 apresentam-se as curvas resultantes da DTG das argamassas.

Pelas análises por DRX e ATG-DTG verifica-se que não houve qualquer formação de compostos por reacção entre os minerais de argila da terra e a cal aérea (PIMENTA et al., 2014). Assim, assumese que o efeito da substituição de cal por terra é apenas físico.

\section{Condutibilidade térmica, capilaridade e secagem}

A condutibilidade térmica $(\lambda)$ das argamassas é apresentada na Tabela 5. Verifica-se uma reduzida variação entre as argamassas, todas elas com

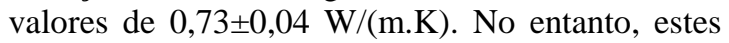
valores são semelhantes e chegam a ser menos de metade dos apresentados por argamassas cimentícias com agregados leves, tal como se pode observar em Brás, Leal e Faria (2013).

\section{Figura 4 - Curvas de intrusão incremental de mercúrio função do diâmetro dos poros das argamassas}

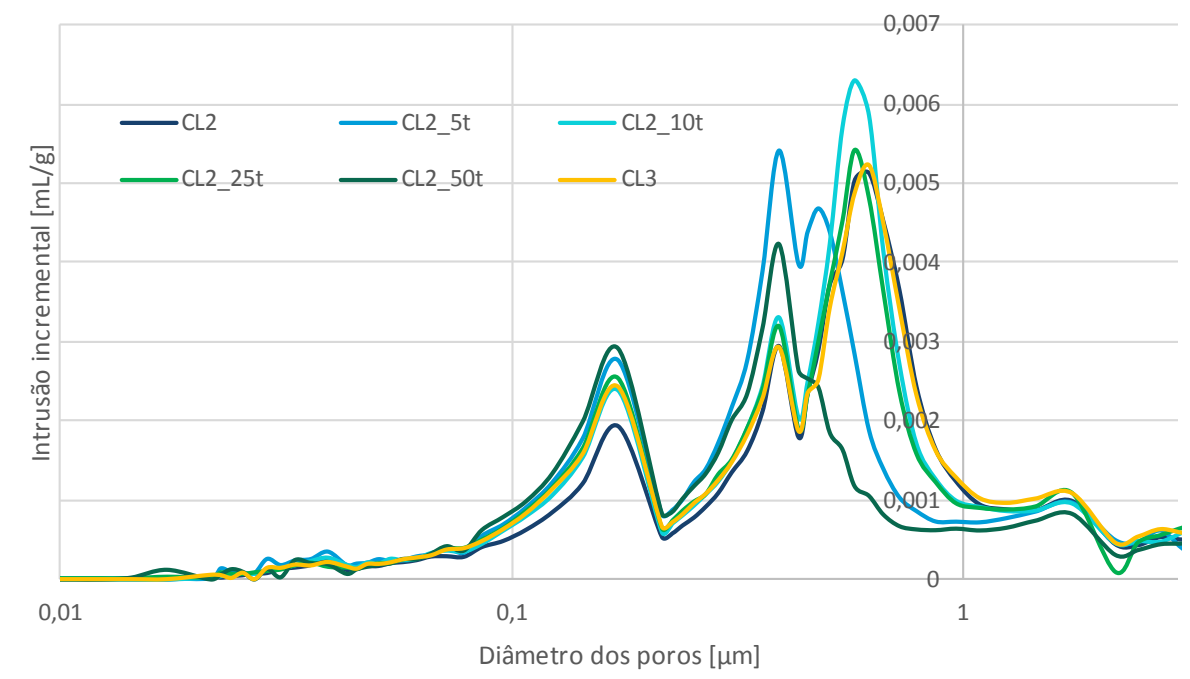

56 Faria, P. 
Figura 5 - Difratogramas das argamassas CL2, CL2_10t, CL2_25t e CL2_50t

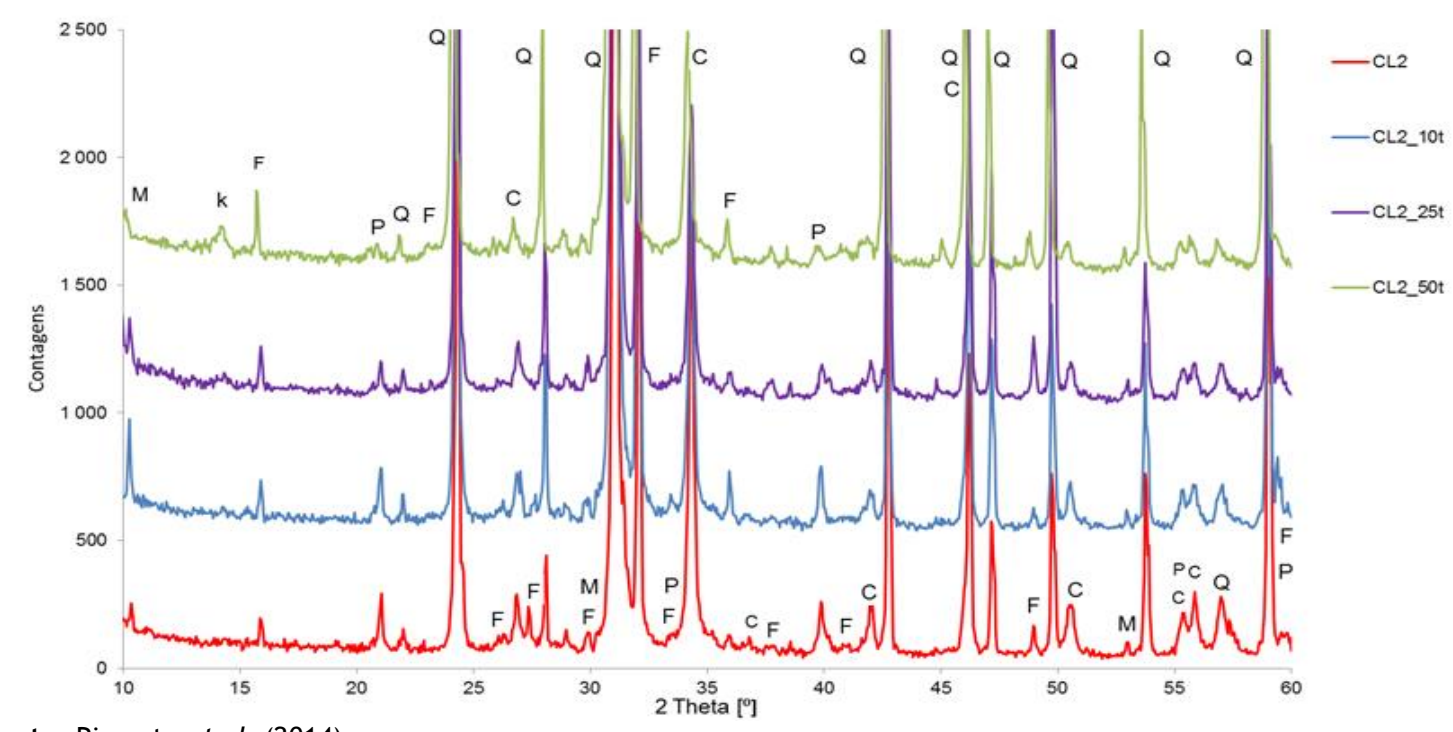

Fonte: Pimenta et al. (2014).

Nota: Legenda:

C-Calcite;

P-Portlandite;

M-Mica;

K- Caulinite;

F-Feldspatos; e

Q-Quartzo.

Figura 6 - Curvas DTG das argamassas CL2, CL2_10t, CL2_25t e CL2_50t

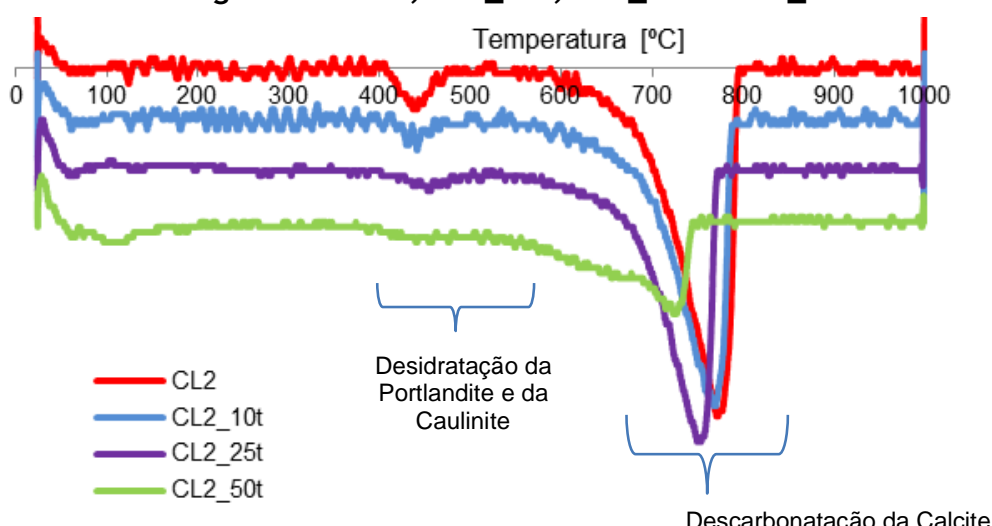

Fonte: Pimenta et al.(2014).

Apresentam-se na Figura 7 as curvas de capilaridade das argamassas e na Tabela 6 os correspondentes coeficientes de capilaridade (CC) e valores assintóticos (VA). Verifica-se que a substituição de cal por percentagens de terra até $10 \%$ diminui o coeficiente de capilaridade e que mesmo a argamassa com $25 \%$ de terra apresenta um CC ligeiramente inferior ao da argamassa de referência CL2. Já a substituição por $50 \%$ de terra produz um aumento do CC. O VA de absorção capilar quase não sofre alteração entre as várias argamassas com traço base 1:2. No entanto, a argamassa de referência CL3 apresenta um CC e um VA inferior a todas as CL2, devido à muito provável redução de capilares.

Apresentam-se na Figura 8 as curvas de secagem das argamassas e na Tabela 6 os correspondentes resultados de taxa da $1^{\text {a }}$ fase de secagem (TS) e índice de secagem (IS). Verifica-se que a TS reduz-se com a substituição de cal até $25 \%$ de terra, aumentando para percentagem de substituição de $50 \%$ e para a argamassa de referência ao traço 1:3. Já o IS, que traduz a dificuldade de secagem total, é particularmente positivo para esta argamassa CL3, o que supostamente encontra justificação na maior 
dimensão de poros desta argamassa, com uma estrutura com poros maiores comparativamente à argamassa CL2. Tal é sugerido pela análise microestrutural, uma vez que a gama principal de poros da argamassa CL3 encontra-se nos $0,8 \mu \mathrm{m}$ enquanto a da CL2 é um pouco menor. Entre as argamassas com base no traço 1:2, o comportamento traduzido pelo IS indicia menor capacidade de secagem das argamassas CL2 comparativamente às argamassas com terra.

Figura 7 - Curvas de capilaridade das argamassas

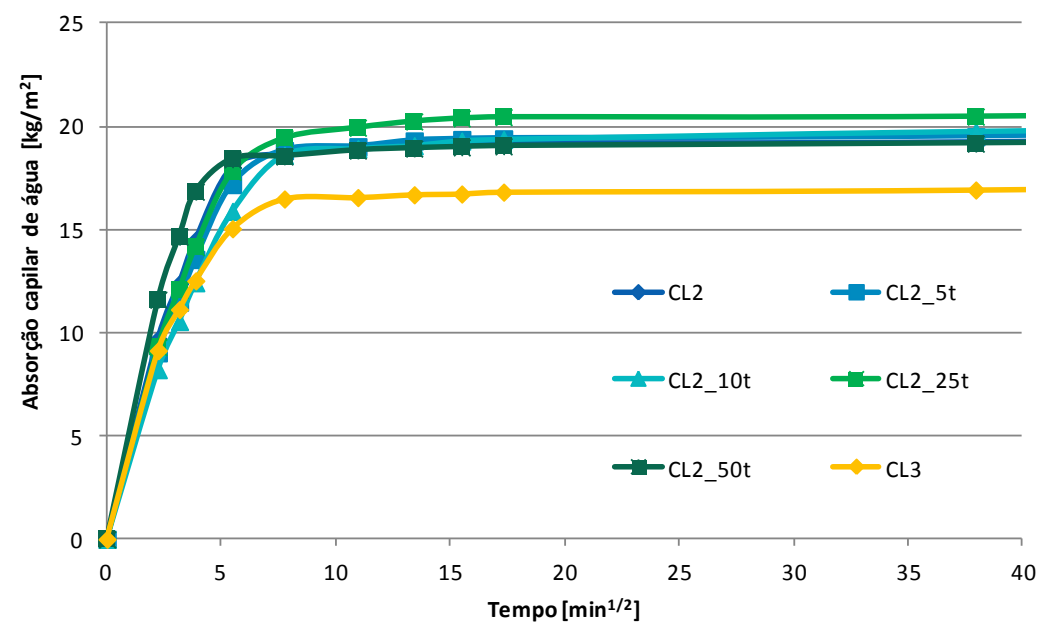

Tabela 6 - Coeficiente de capilaridade, valor assintótico, taxa na fase 1 de secagem, índice de secagem e perda de massa após 25 ciclos de ataque por sulfatos

\begin{tabular}{|c|c|c|c|c|c|c|c|c|c|c|}
\hline \multirow{2}{*}{ Arg. } & \multicolumn{2}{|c|}{$\mathrm{CC}\left[\mathrm{kg} /\left(\mathrm{m}^{2} \cdot \mathrm{min}^{1 / 2}\right)\right]$} & \multicolumn{2}{|c|}{ VA $\left[\mathrm{kg} / \mathrm{m}^{2}\right]$} & \multicolumn{2}{|c|}{ TS $\left[\mathrm{kg} /\left(\mathrm{m}^{2} \cdot \mathrm{h}\right)\right]$} & \multicolumn{2}{|c|}{ IS [-] } & \multicolumn{2}{|c|}{$\Delta$ Massa Sulf. [\%] } \\
\hline & Med & Dp & Med & Dp & Med & Dp & Med & Dp & Med & Dp \\
\hline CL2 & 3,78 & 0,18 & 19,7 & 0,6 & 0,26 & 0,01 & 0,19 & 0,02 & 48,4 & 2,7 \\
\hline & & 0 , & 20,0 & 0,3 & & 0,01 & & & & 1,8 \\
\hline CL2_10t & 3,2 & 0,17 & 20,2 & 0,6 & 0,24 & 0,01 & 0,16 & 0,00 & 43,6 & 4,5 \\
\hline CL2_25t & 3,70 & 0,17 & 20,9 & 0,3 & 0,23 & 0,04 & 0,18 & 0,03 & 59,1 & 0,4 \\
\hline CL2_50t & 4,42 & 0,01 & 19,5 & 0,3 & 0,28 & 0,02 & 0,15 & 0,01 & 64,9 & 0,9 \\
\hline CL3 & 2,76 & 0,23 & 17,4 & 0,5 & 0,30 & 0,02 & 0,10 & 0,01 & 42,3 & 2,5 \\
\hline
\end{tabular}

Figura 8 - Curvas de secagem das argamassas

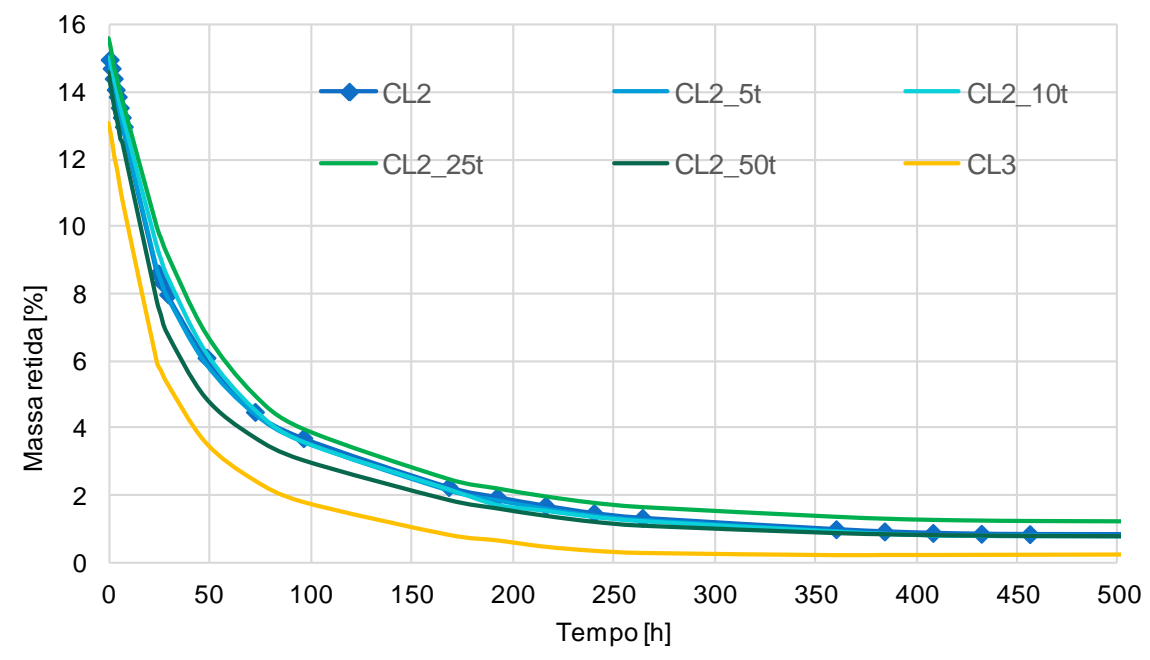

58 Faria, $\mathrm{P}$. 


\section{Resistência ao ataque por sulfatos}

Apresentam-se na Figura 9 as variações de massa por ação de sulfatos ao longo dos ciclos e na Tabela 6 a perda de massa ao fim de 25 ciclos ( $\Delta$ Massa Sulf.). Verifica ainda que, ao longo do ensaio, a degradação ocorre sempre superficialmente, por falta de coesão do material na envolvente exterior do provete. Daí haver uma correspondência inversa entre a resistência à compressão das argamassas e a correspondente perda de massa por ação dos sulfatos. Visualmente não se observa a formação de composto químico expansivo que provocasse rotura no seio das argamassas, ao contrário do que ocorre frequentemente em argamassas cimentícias (FARIA, 2009).

\section{Conclusões}

Uma vez que os valores mínimos de resistência à compressão de todas as argamassas de cal com terra analisadas $\left(0,51 \mathrm{~N} / \mathrm{mm}^{2}\right)$ são superiores aos mínimos definidos para argamassas para aplicação em rebocos $\left(0,40 \mathrm{~N} / \mathrm{mm}^{2}\right)$, considera-se que, do ponto de vista mecânico, as argamassas ensaiadas são adequadas para aplicações em alvenarias antigas ou com características similares. De entre as argamassas de cal aérea com terra analisadas, a com $10 \%$ de substituição de cal por terra demonstra ser bastante eficiente, não só em termos mecânicos, mas também em termos de comportamento face à água, para aplicação como reboco e também para refechamento de juntas. Mas esta formulação de reboco com $10 \%$ de terra não foi aplicada no murete de taipa. No entanto, observando visualmente ao longo de cinco anos o comportamento do reboco com $25 \%$ de terra aplicado no murete de taipa, regista-se um estado equivalente ao do reboco só de cal também aplicado no murete: sem ocorrência de fendilhação e boa durabilidade. Para além dos aspectos técnicos analisados, as argamassas de cal com terra apresentam ainda uma ligeira pigmentação natural, que pode ser interessante em termos estéticos para determinadas aplicações.

Nas argamassas de cal com terra analisadas efetuou-se uma substituição em massa de cal aérea por terra. A terra apresenta uma massa específica muito superior à da cal. Isto significa que, na substituição, um determinado volume de cal foi substituído por um volume muito inferior de terra. Assim, interessa também aferir se argamassas em cujas formulações se mantenham os volumes (em vez de as massas) nas substituições de cal por terra, os resultados poderão vir a ser ainda otimizados.

Assim, o uso desta terra como constituinte parcial de argamassas de cal aérea mostra ser uma medida que tecnicamente pode ser eco-eficiente, pela possibilidade de obter características adequadas às aplicações das argamassas, através da sua formulação com menor consumo de recursos de matérias-primas e energia. Com efeito, a substituição parcial de cal por terra local, proveniente de escavações, será particularmente ecológica uma vez que reduz a necessidade de transporte da terra para aterro e reduz a necessidade de exploração de pedra calcária e de energia calorífica para a produção de cal. A terra necessitará apenas de um desterroamento e peneiração para eliminação de partículas de grandes dimensões, não compatíveis com as aplicações das argamassas.

Simultaneamente, as argamassas serão potencialmente menos onerosas, o que pode facilitar a sua aplicação não só em construção nova mas também na reparação de rebocos e no refechamento de juntas existentes no património edificado, assegurando a compatibilidade e, inerentemente, a proteção das respectivas alvenarias. 
Figura 9 - Variação de massa das argamassas ao longo dos ciclos de ataque por sulfatos

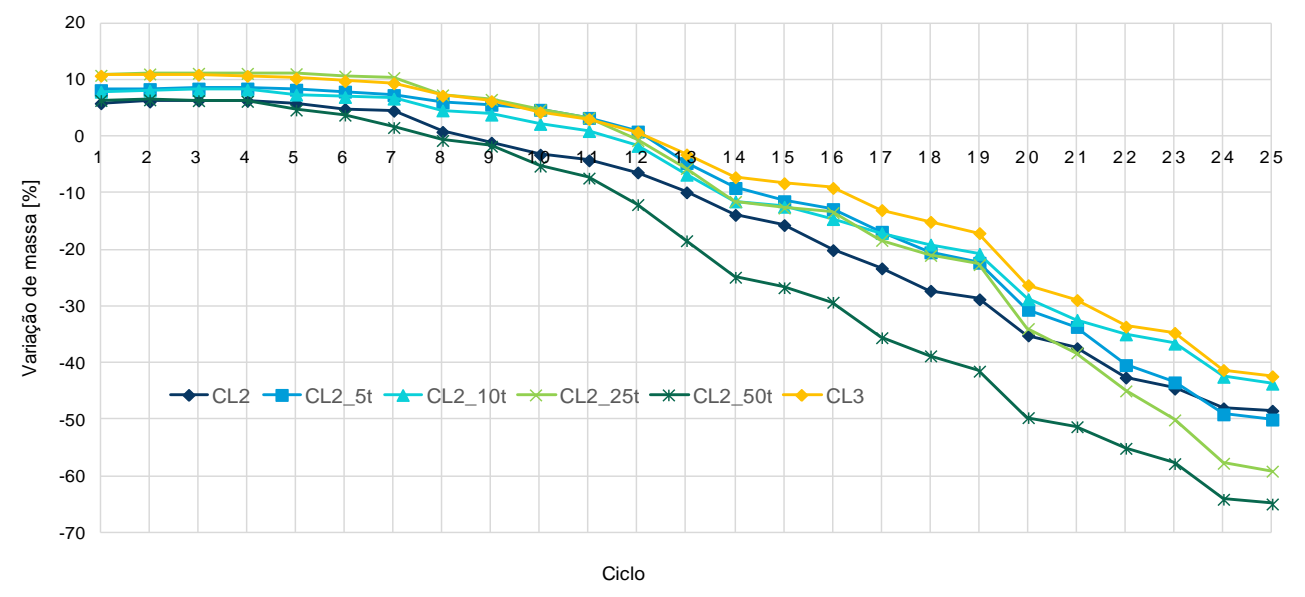

Considera-se, assim, que tal justifica a continuidade do estudo de argamassas de cal e terra, com vista a uma mais aprofundada caracterização e otimização de potenciais formulações. Embora sem se poder ainda comprovar, admite-se que a situação possa ser semelhante quando se utilizar uma terra ilítica em vez da caulinítica utilizada neste estudo. No entanto, considera-se que não se deve usar uma terra com argila montmorilonítica pela elevada retração associada a este tipo de argila.

\section{Referências}

BRÁS, A.; LEAL, M.; FARIA, P., Cement-Cork mortars for thermal bridges correction: comparison with cement-eps mortars performance.

Construction and Building Materials, v. 49, p. 315-327, 2013.

CARDOSO, C.; EIRES, R.; CAMÕES, A. Natural Fibre Reinforced Earth and Lime Based Mortars. In: PORTUGAL SB13 - CONTRIBUTION OF SUSTAINABLE BUILDING TO MEET EU 2020-20 TARGETS, Guimarães, 2013.

Anais...Guimarães: Universidade do Minho, 2013.

\section{COMITE EUROPEENNE DE}

NORMALISATION. EN 1015-1, A1: methods of test for mortar for masonry: part 1: determination of particle size distribution (by sieve analysis). Brussels, 1998.

\section{COMITE EUROPEENNE DE}

NORMALISATION. EN 1015-11, A1: methods of test for mortar for masonry: part 11: determination of flexural and compressive strength of hardened mortar. Brussels, 1999.

\section{COMITE EUROPEENNE DE}

NORMALISATION. EN 1015-18: methods of test for mortar for masonry: part 18: determination of water absorption coefficient due to capillary action of hardened mortar. Brussels, 2002.

\section{COMITE EUROPEENNE DE}

NORMALISATION. EN 1015-3, A1, A2:

Methods of test for mortar for masonry: part 3: determination of consistence of fresh mortar (by flow table). Brussels, 1999.

\section{COMITE EUROPEENNE DE}

NORMALISATION. EN 15801: conservation of cultural property:test methods: determination of water absorption by capillarity. Brussels, 2009.

\section{COMITE EUROPEENNE DE}

NORMALISATION. EN 16322: conservation of cultural heritage: test methods: determination of drying properties. Brussels, 2013.

DARLING, E. et al. Impacts of Clay Plaster on Indoor Air Quality Assessed Using Chemical and Sensory Measurements. Building and Environment, v. 57, p. 370-376, 2012.

FARIA, P.et al.Air Lime-Earth Blended Mortars: assessment on fresh state and workability. In: EARTHEN ARCHITECTURE - PAST, PRESENT AND FUTURE. London: CRC Press, 2015.

FARIA, P. et al. Evaluation of Air Lime and Clayish Earth Mortars for Earthen Wall Renders. In: VERNACULAR Heritage and Earthen Architecture: contributions for sustainable development.London: CRC Press, 2013.

FARIA, P. Resistance to Salts of Lime and Pozzolan Mortars. In: INTERNATIONAL RILEM WORKSHOP ON REPAIR MORTARS FOR HISTORIC MASONRY, Delft, 2005.

Proceedings....Paris: RILEM Publications, 2009. 
FARIA, P.; HENRIQUES, F.; RATO, V. Comparative Evaluation of Aerial Lime Mortars for Architectural Conservation. Journal of Cultural Heritage, v. 9, n. 3, p. 338-346, 2008.

FARIA, P.; LIMA, J. Rebocos de Terra. Cadernos de Construção com Terra, v. 3, Argumentum, 2018.

FARIA, P.; SANTOS, T.; AUBERT, J.-E. Experimental Characterization of an Earth Ecoefficient Plastering Mortar. Journal of Materials in Civil Engineering, v. 28, n. 1, p. 04015085, 2016.

FARIA, P.; SANTOS, T.; SILVA, V. Earth-Based Mortars for Masonry Plastering. In: INTERNATIONAL MASONRY CONFERENCE, 9, Guimarães, 2014. Proceedings... Guimarães, 2014.

GAMEIRO, A. et al. Physical and Chemical Assessment of Air Lime-Metakaolin Mortars: influence of binder:aggregate ratio. Cement and Concrete Composites, v. 45, p. 264-271, 2013.

GOMES, M. I.Conservação de Paredes de Taipa: argamassas de reparação. Caparica, 2013. 248 f. Tese (Doutoramento em Engenharia Civil) Universidade Nova de Lisboa, Caparica, 2013.

GOMES, M.I.; FARIA, P.; GONÇALVES, T.D., Earth-Based Mortars for Repair and Protection of Rammed Earth Walls: stabilization with mineral binders and fibers. Journal of Cleaner Production, v. 172, p. 2401-2414, 2018.

GOMES, M. I.; GONÇALVES, T.; FARIA, P.Hydric Behavior of Earth Materials and the Effects of their Stabilization with Cement or Lime: Study on Repair Mortars for Historical Rammed Earth Structures. Journal of Materials in Civil Engineering, v. 28, n. 7, p. 04016041, 2016.

HAMARD, E. et al. A Procedure to Assess the Suitability of Plaster to Protect Vernacular Earthen Architecture. Journal of Cultural Heritage, v. 14, p. 109-115, 2013.

INSTITUTO PORTUGUÊS DA QUALIDADE. NP EN 12370: métodos de ensaio para pedra natural: determinação da resistência à cristalização de sais. Caparica, 2001.

INSTITUTO PORTUGUÊS DA QUALIDADE. NP EN 14146: métodos de ensaio para pedra natural: determinação do módulo de elasticidade dinâmico (através da medição da frequência de ressonância fundamental). Caparica, 2006.
INSTITUTO PORTUGUÊS DA QUALIDADE.

NP EN 1936: métodos de ensaio para pedra natural: determinação das massas volúmicas real e aparente e das porosidades total e aberta. Caparica, 2008.

INSTITUTO PORTUGUÊS DA QUALIDADE. NP EN 998-1: especificação de argamassas para alvenarias: parte 1: argamassas para rebocos interiores e exteriores. Caparica, 2013a.

INSTITUTO PORTUGUÊS DA QUALIDADE. NP EN 998-2: especificação de argamassas para alvenarias: parte 2: argamassas de assentamento. Caparica, 2013b.

LIMA, J.; FARIA, P. Eco-Efficient Earthen Plasters: the influence of the addition of natural fibers. In: NATURAL Fibres: advances in science and technology towards industrial applications. Berlin: Springer, 2016.

LIMA, J.; FARIA, P.; SANTOS SILVA, A. Earthen Plasters Based on Illitic Soils from Barrocal Region of Algarve: Contributions for Building Performance and Sustainability. Key Engineering Materials, v. 678, p. 64-77, 2016.

MELIÀ, P. et al.Environmental Impacts of Natural and Conventional Building Materials: a case study on earth plasters. Journal of Cleaner Production, v. 80, p. 179-186, 2014.

MORTON, T.; LITTLE, R. Conserving Earth Mortared Monuments in a Damp Climate. In: HISTORIC MORTARS CONFERENCE, 3., Glasgow, 2013. Proceedings... Glasgow, 2013.

PIMENTA, P. et al. Caracterização de Argamassas de Cal Aérea e Terra. In: SIMPÓSIO DE ARGAMASSAS E SOLUÇÕES TÉRMICAS DE REVESTIMENTO, 1., Coimbra, 2014. Anais... Coimbra, 2014.

SANTOS, T.; NUNES, L.; FARIA, P., Production of Eco-Efficient Earth-Based Plasters: influence of composition on physical performance and biosusceptibility. Journal of Cleaner Production, v. 167, p. 55-67, 2017.

VEIGA, R. Air Lime Mortars: what else do we need to know to apply them in conservation and rehabilitation interventions? A review.

Construction and Building Materials, v. 157, p. 132-140, 2017.

\section{Agradecimentos}

Agradece-se ao Mestre Vitor Silva e aos alunos e ex-alunos que, ao longo dos anos, têm participado no estudo de argamassas de terra, de cal e de cal com terra. Este estudo insere-se no âmbito do projecto PTDC/EPH-PAT/4684/2014: DB- 
HERITAGE - Base de dados de materiais de construção com interesse histórico e patrimonial.

CERIS | Departamento de Engenharia Civil, Faculdade de Ciências e Tecnologia | Universidade NOVA de Lisboa | 2829-516 | Caparica Portugal | Tel.: +351 212948580 | E-mail: paulina.faria@fct.unl.pt

\section{Revista Ambiente Construído}

Associação Nacional de Tecnologia do Ambiente Construído

Av. Osvaldo Aranha, $99-3^{\circ}$ andar, Centro

Porto Alegre - RS - Brasil

CEP $90035-190$

Telefone: +55 (51) 3308-4084

Fax: +55 (51) 3308-4054

www.seer.ufrgs.br/ambienteconstruido

E-mail: ambienteconstruido@ufrgs.br

62 Faria, P. 